\section{SAAAA \\ JOURNAL}

Open Access
Journal of Archaeology and Fine Arts in

Southeast Asia

Published by the SEAMEO Regional Centre for Archaeology and Fine Arts (SPAFA)

\title{
The Mak Yong Dance Theatre as Spiritual Heritage: Some Insights
}

Prof. Dr Ghulam-Sarwar Yousof Adjunct Professor, Cultural Centre University of Malaya

Malaysia



\begin{abstract}
This paper was presented as the keynote address at the Mak Yong Spiritual Dance Heritage: Seminar and Performances, organized by SEAMEO SPAFA in collaboration with the Thai Khadi Research Institute, Thammasat University, on 20-21 September 2011 at Thammasat University, Bangkok. It is part of an upcoming collected edition of papers presented at the seminar.
\end{abstract}

Keywords: mak yong, mengadap rebab, ritual theatre, oral tradition, intangible heritage

\section{Introduction}

\section{Identity of Mak Yong}

Makyong is an ancient dance-theatre form incorporating the elements of ritual, stylized dance and acting, vocal and instrumental music, song, story, and formal as well as improvised spoken text. It is principally performed in the two provinces of Patani in southern Thailand and Kelantan in Malaysia on the east coast of the Malay Peninsula, as well as, to some extent, in the Riau Islands of Indonesia. On the 
peninsula, mak yong was also active in the state of Kedah at one time. Mak yong troupes from the Malay Peninsula are known to have travelled to northern Sumatra in Indonesia, where they received some royal support in the province of Deli, while in the Riau Islands of Indonesia occasional performances are still staged.

Mak yong performances may be classified into two broad categories - those intended for entertainment and those, ritualistic in character, performed on the occasion of salutation to teachers (semah guru) as well as in situations requiring particular kinds of healing. Due to the history of its development as well as local circumstances, there are also significant differences between mak yong styles and techniques in the three countries where it is active.

\section{Origins and History}

The antiquity of mak yong makes it unlikely that any historical record dealing with its early phases will ever be located. No classical literary or historical work (hikayat) has mentioned it. This situation has given rise to several often starkly contrasting, even contradictory, views regarding its origins. To summarize, the first perceives mak yong as arising out of rituals connected with the spirit or goddess of rice (semangat padi), named by some as Mak Hiang, with the precise identity of Mak Hiang herself being clearly confused. The next indicates the possibility of mak yong arising out of imitation of natural phenomena. The third, that it developed out of rituals connected with the propitiation of and the fecundity of the earth or with the earth (bumi) itself seen as a goddess. The fourth holds that mak yong grew out of shamanic rituals. All of these views link mak yong in different ways to natural phenomena, or to cults of spirits, ancestors or ancient deities, particularly Semar.

A second, alternative strain in origin theories gives emphasis to the possibility that mak yong has, from its very inception until recent times, always been a highly important form of court theatre or royal entertainment. It is said to have been actively performed in the kingdom of Langkasuka, following which it was "inherited" by royal houses in Ligor, Patani and Kelantan. In all of these cases, however, there is no evidence of any sort to confirm the very existence of mak yong.

Based on the fact that even the precise locality of Langkasuka and its geographical extent remain unknown and that not a single name of a royal dynasty or ruler of that ancient kingdom has come down to us, to hold a view of mak yong's supposed strong connections with it and with its royal dynasties is altogether illogical, even fantastical. To hold and to promote a view that mak yong was not only actively performed, but that it was the favourite entertainment of generations of Malay rulers is absurdity itself when the issue of Langkasuka, a so-called "Malay" kingdom itself remains to be settled. Similarly, many issues with regard to mak yong in Patani as well as in Kelantan remain unclear. It may be noted that even in the Hikayat Patani, the most reliable source for the history of Patani in the $17^{\text {th }}$ century, much quoted as providing "evidence" for the existence of mak yong in that important kingdom, does not mention this genre of theatre in its pages while yet devoting generous space to other court entertainments.

These views are further complicated by the attempt to merge the two distinct theories by connecting Mak Hiang to royalty, turning her into some kind of patron goddess actively involved in court matters or as an intermediary between royalty and unidentified higher beings. 
When it comes to the known history of mak yong, two dates are significant. In 1878, Frank Swettenham happened to see a performance by a small itinerant group in Pahang. In the 1930s, Tengku Temenggong Abdul Ghaffar (1875-1935) of Kelantan tried, unsuccessfully, to create a refined version of mak yong in Kota Bharu, perhaps in imitation of the practice in Javanese, Cambodian and Thai kingdoms whose rulers are known to have actively supported the performing arts. It is notable that the artists brought into Kampung Temenggong were from rural groups, several of which are known to have been active in Kelantan during his time. Both instances indicate that mak yong was a folk theatre form.

This situation has been totally ignored, and the official view in Malaysia has, in recent decades, been that mak yong was always a form of court theatre. This is a deliberate misrepresentation of the known facts, something promoted actively in the first instance by a European, whose motives we can only guess, and then sustained by national policy to this day. The basis for this is the sole initiative of Tengku Temenggong Abdul Ghaffar.

In 1970-71, with the establishment of the Kumpulan Seri Temenggong under the leadership of Khatijah Awang (1941-2000), an altogether new kind of mak yong, pretentious, glamorous, and highly artificial, came into being. The very name of the group is symbolic of certain dreams and aspirations that, belonging initially to a small group of interested parties, were taken over by the "custodians" of national heritage. It is significant that besides Kumpulan Seri Temenggong no other Malaysian group performed this new variety of mak yong. Following the passing away of Khatijah Awang and the end of Seri Temenggong with her, there have been pale imitations of its kind of mak yong by members of the same extended family. The Seri Temenggong style also continues to be actively promoted by the National Arts and Heritage Academy and by the National Theatre, Istana Budaya, in the latter case with further embellishments in keeping with its supposed aim to take this form of ritual theatre onto the world stage. With the considerable shift away from what makyong used to be, the question inevitably arises: Is this still mak yong? To this issue we will return.

Meanwhile in rural areas, the traditional folk style of mak yong continues, often in combination with the main puteri shaman dance. There can be nothing greater than the stark contrast between these two strains of what is supposedly the same genre of theatre. This becomes intensely obvious when one takes a close look at the inner core of mak yong: its spiritual heritage.

In keeping with this theme of the seminar, it may be pertinent to focus on a few relevant aspects of mak yong. The origins have been discussed. Apart from the dramatic repertoire and its principal characters, the types of mak yong performances, the purposes for which this theatre genre was and still continues to be performed in its traditional setting and the importance of mak yong itself are worthy of attention.

\section{Dramatic Repertoire and Characters}

Mak yong stories, traditionally believed to have been twelve in number, are said to have expanded in stages from a single story, Dewa Muda, which is by far the most important, for it is believed to encapsulate the origins of mak yong itself. Other significant stories include Dewa Pechil, Anak Raja Gondang and Raja Tangkai Hati.

The origins of majority of the mak yong stories remain unknown. They are not based upon the usual sources such as the Ramayana and Mahabharata that have been extensively used in the traditional theatre in the region. Nor do they belong to any local epics or Asian literature. The repertoire is usually divided into two categories 
comprising the twelve core stories and the extended repertoire of another dozen or so secondary plays. A small number of the latter are derived from lakon chatri or menora, from the now extinct wayang kulit Melayu and even the comparatively recent bangsawan theatre. Performers in Kelantan propose Javanese origins for Dewa Muda and Dewa Pechil, identifying Dewa Muda, in particular, with Raden Inu Kertapati, the hero of the important and highly popular Panji romances which, originating in pre-Islamic Central Java, found a footing in the Malay Peninsula, Thailand and Cambodia. Much of the dramatic repertoire, however, has remained inactive since its existence was first noticed due to the small number of active troupes at any one time, the rarity of performances and the reasons for which mak yong was traditionally staged.

Apart from Dewa Muda and Dewa Pechil, there are other important aesthetic elements in mak yong which link it strongly with Javanese cultural traditions. Such a situation almost certainly came about as a result of historical and cultural connections between Java (as well as possibly Sumatra) and the Kelantan-Patani region of the Malay Peninsula. A small number of mak yong plays are actually set in Java or Sumatra.

The most important Thai-Buddhist story in mak yong's core repertoire is Anak Raja Gondang. This is a local version of the Thai Sang Thong (Prince of the Golden Shell), one of the extra-canonical (pinnasa Jataka) stories of the Buddha's previous lives believed to have been written down for the first time in northern Thailand. The extended repertoire contains other such stories connected with Thai theatre or folk literature. Further investigations may also reveal connections with territories further north, particularly with Champa, as well as indigenous myths now lost.

Almost all mak yong plays deal with adventures of gods (dewa) or mythical kings (raja) as well as supernatural events. Performers regard all these stories with a measure of awe due to the presence of gods and semi-divine or supernatural beings as principal characters.

\section{New Approach to Dramatic Texts}

Makyong texts existed entirely in the oral tradition until recent efforts to document them. Oral transmission has led to the existence of several plays in various versions. Dewa Muda, for instance, can be found in Kelantan in two major and other minor versions according to its line of transmission and functions. In the Riau islands, the mak yong play is entitled Wau Bermas or Layang Bermas (both meaning Golden Kite) and is considerably different from its Malaysian counterpart. In Kelantan, Dewa Muda and Dewa Pechil have a central position in ritual performances done for initiation rites (sembah guru) of mak yong actresses as well as for healing. In terms of spiritual value, the two plays are by far the most important in the entire mak yong repertoire. Others attain similar importance in particular situations, depending upon the artists and musicians involved.

Considering mak yong's core plays as not purely as performance texts but also as essential elements in rituals, it is clear that a new way of looking at them is needed. The familiar method which places emphasis on plot or character has only limited validity. In ritual performances, focus rests upon particular episodes in the plays, episodes efficacious in bringing about healing, or inner renewal. Priority is thus given to such key scenes over complete plots, which may not even be performed in full. This situation parallels a shift in the meaning and significance of principal characters 
in psychological or symbolic terms in keeping with universal tendencies in mythology. These episodes, remarkably consistent in the orally transmitted texts, are said to be magically and spiritually important by virtue of the central figure's role and meaning in the performance. It is also noteworthy that such episodes achieve their fullest power as well as desired ends most effectively through the total fusion of spoken and sung words, music, movement or dance as well as ritual activities.

\section{Types of Mak Yong Performances}

Mak yong performances can best be examined in terms of two broad categories: those intended for ritual purposes and those serving the function of entertainment, these latter developing out of the former. Yet, although convenient, such a division is not entirely valid for spiritual and ritual elements remain deeply embedded in the heart of mak yong, no matter what shape the performances assume.

\section{Ritual Mak Yong and Mak Yong as Ritual}

The earlier discussion of mak yong origins has indubitably established that this form of theatre had its genesis in rituals. Two important elements may be noted at this point. Firstly, that ritual mak yong continues to be performed in rural Kelantan to this day in combination with main puteri, for purposes of initiation as well as healing. Secondly, that even the so-called entertainment performances cannot be staged without some such activity. Main puteri is also performed by itself as a means of curing the loss of vital energy (semangat) or possession by malicious spirits (hantu).

Lasting over three nights, mak yong's highly complex berjamu performances mark the completion of a novice's training with the salutation of teachers (sembah guru). They also serve the purpose of wind blandishment (menyemah angin) in combination with main puteri, making use of appropriate stories depending upon the type of angin (wind or affliction) affecting a patient.

In such performances, it is not a matter of rituals being added on to theatre, something quite common in many traditions of the world. A berjamu performance is effectively a ritual in its entirety. The designation mak yong berjamu indicates that such performances involve sacrifices or offerings (jamuan, literally a feast) for spirits (hantu, jin, jambalang) as well as gods (dewa). In reality, to take things just one step further, there is the implication that, above and beyond the food offerings, an entire performance itself serves as an offering or jamuan to the gods and spirits. These complex performances do not aim to please any human audience but the invisible host. In every way then, there comes about a significant diminution in the elements of performance - only certain mak yong plays, particularly Dewa Muda and Dewa Pechil, are used, and even these are truncated, with sections narrated rather than actually staged, clearly without the intention to develop a complete plot. Music and dance are reduced, while ritual elements, including trances, are considerably enhanced. Being rituals, such performances do not conform to a pre-ordained structure; rather they are guided by the contingencies of the situation. The important thing is to ensure that none of the core ceremonies are omitted.

\section{Entertainment Mak Yong}

It has been mentioned before that "entertainment mak yong" may have come about following its separation from "ritual mak yong". In recent decades, such a separation has been accelerated by aims that have very little to do with theatre, or even with mak yong aesthetics. This has resulted in a great deal of artificiality, particularly with the 
shift of mak yong into urban areas and the deliberate attempt to "refine" it, supposedly in keeping with a royal tradition which, as made amply clear, was non-existent. Entertainment performances have to some extent always existed in rural Kelantan, as indicated by whatever little has been garnered through the oral record. What is noteworthy, however, is that there is a strong connection between ritual and entertainment, whether these are staged in the villages or even in more sophisticated urban environments.

These vital connections come through the following: the stories, the ritual activities, particularly those connected with the opening and closing section of the play, and the absolute requirement for the mengadap rebab.

The significance of these basic rituals has already been examined, and despite recent objections on account of religious considerations, they continue to be done with minor adjustments, to take into account the encroaching influence of Islam upon the lives of the Malays. The continued performance of these rituals, no matter how disguised or watered down, and the stories illustrate a major contradiction in the current artistic and religious situation in Malaysia, as far as mak yong is concerned.

The stories, which belong exclusively to mak yong, represent the single most important element in mak yong as an art form. They constitute the identity of the genre. It is noteworthy that the dramatic repertoire of the genre has never been written down. Yet the plays and even the texts of the most important plays have been handed down faithfully, hardly changed in over hundreds of years. The essential elements of the texts have remained constant despite much improvisation. This can be possible only in cases where the texts have a more than superficial value as stories, perhaps seen in the context of mak yong itself as sacred art.

When it comes to rituals, the mengadap rebab draws our attention to itself. This is the most important of the three elements mentioned here. It is also, as will be presently shown, a major ritual.

\section{Mengadap Rebab}

Mengadap rebab, the obligatory opening dance of every mak yong performance is accompanied by lagu mengadap rebab, an elaborate song sequence. It is the most beautiful and complex of all dances in mak yong. Our concern here is not with the movements, and even with its specific imagery in terms of their considerable aesthetic values, but its very character and role. This dance is in fact a ceremonial activity, a rite. As its name suggests, mengadap rebab, in its totality as dance and song, constitutes homage to the rebab, a two-stringed fiddle. An inevitable question arises: Why is it necessary to pay homage to a mere musical instrument? The answer to this lies in the symbolic and spiritual meaning of the rebab itself. It is, according to some informants, a symbol of the guru, not the immediate teacher of the mak yong dancer or dancers, but of the ultimate teacher (guru yang asal, guru yang mula) who must remain unnamed given the sensitivities surrounding this idea. The mengadap rebab, then, reiterates the spiritual and religious meaning of mak yong itself through the homage paid to teachers, ancestors and gods, or possibly a particular deity.

The lyrics introduce another dimension to all of this, for a large section of mengadap rebab deals with the preparation of the mak yong actress to assume the role of pak yong, and pak yong in turn represents a king, or more likely, in keeping with the mak yong's dramatic repertoire, a god-king (devaraja). This idea of the god-king stands out in a berjamu performance of mak yong where Dewa Muda and Dewa 
Pechil assume identities far beyond those of princes or romantic heroes. Mengadap $r e b a b$, then, is all these things and even more. In it are ensconced the spiritual meanings of mak yong as suggested in disguised or confused manner in theories attempting to explain its origins and the very purposes for its existence.

\section{Importance of Mak Yong as Spiritual Heritage}

Malaysians are fond of quoting Mubin Sheppard to the extent that he has become a dewa. They are fond of talking about the magic of mak yong, words first put together in that order by him. Significantly, one of the failed attempts to get UNESCO recognition was the inclusion in its documentation or candidature file, a VCD entitled Mak Yong: the Magical Dance Theatre. But what is this magic? The fact that no one, including the white dewa, has ever explained this or even attempted to do so shows how un-seriously the genre has been taken, to the extent that magic becomes just a meaningless catchword like many in the tinsel world of pop-culture or tourism.

The discussion above has demonstrated the extreme importance of mak yong as an art form. It is unique in every way with its content, music, its quiet inner beauty and some of its values. More importantly, it has established the essentially spiritual nature of mak yong. This is something neither as yet adequately explored nor understood. I believe that to fully appreciate it, one has to approach mak yong with an eye not just on its superficial aspects as theatre, but on its inner symbolic and spiritual meaning or meanings that lie buried in its dramatic repertoire, its music and dances and its origins. In this lies the uniqueness of mak yong. This is what makes mak yong invaluable, apart from certain exciting elements within it as a theatre genre. As things stand, mak yong has not been appropriately studied; nor has it been given due recognition by relevant authorities, in this latter case due both to ignorance of its inherent values or too narrow perspective.

All of this means that the art has to be taken seriously, appropriately understood, documented, preserved for posterity, particularly given its fragility. But this can only be possible with an open mind, something seriously lacking in certain quarters. This has led, on the one hand, to an official ban on mak yong in Kelantan by the State authorities and, on the other, to efforts to change it, suit it to particular motives and so on, to the extent that one can question whether its new incarnations are in fact mak yong. In Malaysia, this is one of the many Malay dilemmas.

\section{Decline of Mak Yong and Need for Serious Efforts at Revival}

Serious problems have developed connected with both its survival as well as with preservation and conservation. There are many factors for the decline and nearextinction of mak yong. The picture varies from country to country, and traditional theatre in most countries suffers to some extent from some of the problems faced by mak yong: declining audiences, lack of opportunities to perform, modernization, the popularity of alternative media particularly films, lack of financial support and religious factors.

But Malaysia is perhaps the only country in the world where a highly important genre of traditional performing arts suffers from discouragement on the part of the authorities despite the much-touted international recognition of its unique qualities. On a local level this is actively done, while on a national level it is done by default since no positive steps are being taken to prevent mak yong from decline and ultimate demise. There are also active attempts to shift it away drastically from its innate qualities as an art form. This is highly ironic since, on the one hand, the 
government of Malaysia has a commitment, following the recognition accorded by UNESCO, to make serious efforts to preserve mak yong while, on the other, efforts are indirectly made to change its essential qualities and integral character as an art form, and even to destroy it, if not actively, then certainly through neglect.

\section{UNESCO Recognition}

The proclamation by UNESCO of mak yong as an "Oral and Intangible Heritage of Humanity" in 2005, following the writing of the master plan by the present writer, was an important opportunity for the preservation and conservation of mak yong, in a way to reverse its fortunes. The ambitious plan submitted to UNESCO as part of the Candidature file, prepared on behalf of the Malaysian Ministry of Culture, Arts and Heritage, called for the revival of mak yong with permanent training and performance facilities in Kelantan, Terengganu and Kuala Lumpur. It also called for serious efforts at teaching, research, documentation and promotion both at the national and international levels, all in a period of five to six years. But as things stand today, six years after the recognition, almost nothing or very little has happened. The fact that not even a small portion of the Ministry's own plan has been implemented within the time frame strongly suggests that there was no intention whatsoever in the first place to do anything about mak yong.

Meanwhile, the genre's downward slide has been accelerated. Several veteran artists have gone without any replacements, and today there is hardly anyone who even understands the genre properly, let alone teach it or in any way ensure its continued survival. In the end, all that is likely to remain is what the National Arts and Heritage Academy offers, a modernized student version, a pale shadow of a precious theatre form reaching back over a thousand years.

When it comes to preservation, there are other compelling issues. We have seen the varieties of mak yong that exist and some of the transformations within the genre over the past century or so. Which version of mak yong does one preserve? In the light of the UNESCO recognition accorded to the Malaysian mak yong, we are faced with this new dilemma. The issues are highly important and need to be deliberated. This kind of assembly is certainly one of the channels through which discussion can take place. What happens beyond the discussion is, of course, another thing.

\section{Collaborative Work}

Prospects for collaborative work in mak yong within Malaysia, Indonesia and Thailand, as co-owners or guardians of the mak yong tradition are vitally necessary. Indonesia has been proactive in these matters with the recent proposal for the recognition of mak yong as literature. The Memory of the World proposal is an indication, and also some efforts to make quality recordings of performances available to the rest of the world. This is something that Malaysia and Thailand, in particular, can and should emulate.

\section{Selected Bibliography}

Cuisinier, J (1936) Danses Magiques de Kelantan. Paris: Institut D'Ethnologie. Endicott, KM (1960) An Analysis of Malay Magic. Kuala Lumpur: Oxford University Press.

Geertz, C. (1960) The Religion of Java. Glenco: Illinois Free Press. 
Ghulam-Sarwar Yousof (1976) The Kelantan Mak Yong Dance Theatre: A Study of Performance Structure. PhD Thesis, University of Hawaii, Honolulu.

Ghulam-Sarwar Yousof (1983) Buka Panggung: Theatre Consecration Rituals in the Mak Yong Dance Theatre of Kelantan, Malaysia. Tenggara 16: 55-72.

Ghulam-Sarwar Yousof (1993) Panggung Semar: Aspects of Traditional Malay Theatre. Petaling Jaya, Malaysia: Tempo Publishing (M) Sdn Bhd.

Ghulam-Sarwar Yousof (1994) Dictionary of South-East Asian Traditional Theatre. Kuala Lumpur: Oxford University Press.

Ghulam-Sarwar Yousof (1994) (ed.) The Encyclopedia of Malaysia Volume 8: Performing Arts. Singapore: Editions Didier Millet, Archipelago Press.

Ghulam-Sarwar Yousof (2004) Panggung Inu: Essays on Traditional Malay Theatre. Singapore: UniPress, The Centre for the Arts, National University of Singapore.

Ghulam-Sarwar Yousof (2011) Mak Yong Theatre of Kelantan, Malaysia: An Introduction. Kuala Lumpur: The Asian Cultural Heritage Centre.

Gimlette, JD (1913) Malay Poisons and Charm Cures. London: J \& A Churchill. Reprint, Kuala Lumpur: Oxford University Press, 1971.

Heine-Geldern, R (1942) Conceptions of state and kingship in Southeast Asia. Far Eastern Quarterly 2: 15-30.

Malm, WP (1971) Malaysian ma'yong theatre. The Drama Review 15: 108-144.

Malm, WP (1974) Music in Kelantan, Malaysia and some of its cultural implications. In: WP Malm and A Sweeney (eds) Studies in Malaysian Oral and Musical Traditions. Michigan Papers on Southeast Asia, 8. Ann Arbor, Michigan: University of Michigan Centre for South and Southeast Asian Studies.

Mohd Taib Osman (ed.) (1974) Traditional Drama and Music of Southeast Asia. Kuala Lumpur: Dewan Bahasa dan Pustaka.

Pires, T (1944) The Suma Oriental, trans. and ed. A Cortesao. 2 Vols. London: Haklyut Society.

Rassers, WH (1959) Panji the Culture Hero: A Structural Study of Religion in Java. The Hague: Nijhoff.

Sheppard, M (1960) The Magic Kite and other Ma'yong Stories. Kuala Lumpur: Federal Publications.

Sheppard, M (1969) The text of the sung portion of Dewa Muda and a further note on Ma'yong stories. Federation Museums Journal 14: 45-74.

Sheppard, M (1976) A recording of the ma'yong, the dance drama of Kelantan. Federation Museums Journal 1: 55-103.

Skeat, WW (1972) Malay Magic. New York: Benjamin Blom.

Swettenham, FA (1878) The Malay nautch. Journal of the Straits Branch of the Royal Asiatic Society 2: 163-167.

Teuw, A and Wyatt, DK (1970) Hikayat Patani. 2 Vols. The Hague: Martinus Nijhoff.

Winstedt, RO (1958) The Malay: A Cultural History. London: Routledge and Kegan Paul.

Winstedt, RO (1961) The Malay Magician: Being Shaman, Saiva and Sufi. London: Routledge and Kegan Paul. 